\title{
Perioperative hyperoxia: perhaps a malady in disguise
}

\author{
Yalim Dikmen, Aybike Onur
}

Istanbul University, Cerrahpasa Medical School, Department of Anesthesiology and Reanimation, Turkey

\begin{abstract}
Oxygen is an element, which is used liberally during several medical procedures. The use of oxygen during perioperative care is a controversial issue. Anesthesiologists use oxygen to prevent hypoxemia during surgical procedures, but the effects of its liberal use can be harmful. Another argument for using high oxygen concentrations is to prevent surgical site infections by increasing oxygen levels at the incision site. Although inconclusive, literature concerning the use of high oxygen concentrations during anesthesia show that this approach may cause hemodynamic changes, altered microcirculation and increased oxidative stress. In intensive care it has been shown that high oxygen concentrations may be associated with increased mortality in certain patient populations such as post cardiac arrest patients. In this paper, a review of literature had been undertaken to warn anesthesiologists about the potential harmful effects of high oxygen concentrations.
\end{abstract}

Keywords: hyperoxia, oxidative stress, high oxygen concentrations, general anesthesia

\section{Introduction}

Oxygen is an essential item in modern day medical armory and is amongst the most commonly used drugs in the clinical practice. Its delivery is a simple and effective intervention for acutely ill, especially hypoxemic, patients and most clinical professionals feel comfortable prescribing, and perhaps even overusing it $[1,2]$. No guidelines for perioperative oxygen use exist. Other recent guidelines on oxygen supplementation recommend proper documentation of its use to allow future research and promote second thoughts as increasing evidence suggest inappropriate oxygen use can be harmful rather than purely beneficial [1]. We will review perioperative use of oxygen and the consequences of hyperoxia in surgical patients.

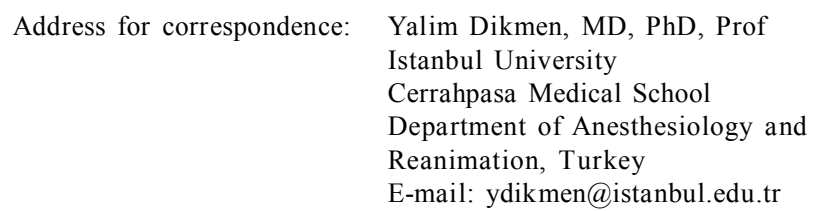

\section{Pathophysiology of high $\mathrm{FiO}_{2}$}

Fraction of inspired oxygen $\left(\mathrm{FiO}_{2}\right)$ is commonly titrated to peripheral capillary oxygen saturation $\left(\mathrm{SpO}_{2}\right)$ measured with pulse oximetry, which can detect hypoxemia but not hyperoxemia [3]. Although a $\mathrm{SpO}_{2}$ level nearing $100 \%$ is intuitively reassuring to prevent risk of life-threatening hypoxemia, increasing $\mathrm{FiO}_{2}$ blindly just to achieve that may have more detrimental effects $[2,4]$. The primary goal of oxygen therapy is to increase oxygen available for aerobic metabolism, but it can also cause damage directly or via molecular sequelae of adverse metabolic alterations in perioperative period.

Circulatory effects of hyperoxia are complex. Hyperoxia causes systemic vasoconstriction and reduces microcirculation $[5,6]$. Cardiac output and organ perfusion may become altered with high $\mathrm{FiO}_{2}$ as heart rate drops, systemic vascular resistance rises and capillary permeability decreases [7]. Pulmonary circulation rises as a result of decreased pulmonary vascular resistance, but there is no confirmed subsequent benefit for the patient and this may even be accompanied by bronchoconstriction [8]. Cerebral vasoconstriction can reduce cerebral blood flow, which 
can be beneficial or harmful depending on the context $[9,10]$. These circulatory consequences may compromise tissue oxygenation contrary to an anticipated increase with a higher $\mathrm{FiO}_{2}$, since tissue oxygenation depends on oxygen delivery to the tissues as well as oxygen content of blood.

Increasing $\mathrm{FiO}_{2}$ is only one of the means of increasing arterial partial pressure of oxygen $\left(\mathrm{PaO}_{2}\right)$ and loading hemoglobin with oxygen $\left(\mathrm{SpO}_{2}\right)$. Together these factors determine oxygen content of the blood along with hemoglobin concentration. Increasing $\mathrm{FiO}_{2}$ only marginally increases oxygen content of the blood when hemoglobin is adequately saturated as evident in the oxyhemoglobin disassociation curve [7]. In addition, a high $\mathrm{FiO}_{2}$ leads to arterial accumulation of dissolved oxygen causing increased reactive oxygen species (ROS) formation. Superoxide, hydroxyl radicals and hydrogen peroxide are ROS formed for physiological purposes, but their excess causes cellular toxicity via increased lipid peroxidation, DNA damage and protein oxidation leading to organ dysfunction [7]. Innate anti-oxidative systems to protect against excess ROS exist; however, they easily become over-saturated and inadequate with increased oxidative stress. High perioperative $\mathrm{FiO}_{2}$ has been shown to increase oxidative stress while limiting antioxidant response [11]. Tissues with high anabolic metabolism are especially prone to the oxidative damage by ROS [12].

Reactive oxygen species are key steps in the formation of bacteriotoxic metabolites such as hypochlorus acid and myeloperoxidases. Although a high $\mathrm{FiO}_{2}$ may increase the ROS available for the host bactericidal defensive actions, it does not increase neutrophil's phagocytic activity or cytokine response [13]. Overall high $\mathrm{FiO}_{2}$ impairs the immune systems' defensive mechanisms by causing actin damage compromising endothelium and macrophages $[14,15]$. A high $\mathrm{FiO}_{2}$ may contribute to the efficacy of antibiotics in preventing infections as many are oxygen-dependent in their effect [16]. Hyperoxia also leads to perturbation in elastin and collagen crosslinking and impairs mechanical aspects of tissue healing [17]. All these intricate and sometimes opposing factors form a complex relationship between $\mathrm{FiO}_{2}$ and perioperative outcomes.

\section{Clinical outcomes of high perioperative $\mathrm{FiO}_{2}$}

Studies of the pathophysiological outcomes of hyperoxia have been conducted in different animal models using variable oxygen levels, each under very specific conditions; therefore, generalization of their outcome and application to clinical practice is limited. Clinical trials to date have been difficult to compile in systemic reviews and meta-analyses to reach a single consensus on oxygen use, because in these studies control and intervention $\mathrm{FiO}_{2}$, timing of the high $\mathrm{FiO}_{2}$ intervention and primary outcome vary greatly and sufficient patient numbers are lacking [4].

Clinical consequences of high $\mathrm{FiO}_{2}$ on the pulmonary system are now widely accepted. Directly, oxygen delivery increases only alveolar partial pressure of oxygen $\left(\mathrm{PAO}_{2}\right)$. When breathing higher than $80 \%$ oxygen, absorptive atelectasis results from the washout of nitrogen from the alveolar space, which then collapses as the remaining absorbable gases diffuse through the tissue $[18,19]$. This atelectasis is also resistant to recruitment maneuvers [20], contributing to the observation that high intra-operative $\mathrm{FiO}_{2}$ decreases end expiratory lung volume and $\mathrm{PaO}_{2} / \mathrm{FiO}_{2}$ ratio in surgical patients [11].

ROS formation in the airway also directly damages alveolar histology and impairs gas exchange [21]. Inhaling high $\mathrm{FiO}_{2}$ can also result in tracheobronchitis leading to dyspnea and pleuritic chest pain in patients undergoing general anesthesia [22]. Chronic obstructive pulmonary disease patients suffer from increased airway inflammation and decreased hypoxic respiratory drive leading to hypercarbia on return to spontaneous inhalation [23]. Even during one lung ventilation, a lower $\mathrm{FiO}_{2}$ adjusted according to $\mathrm{PaO}_{2}$ may lead to a better outcome due to less inflammatory and oxidative injury [24]. A severe manifestation of lung damage can be seen in neonates ventilated with high $\mathrm{FiO}_{2}$ as bronchopulmonary dysplasia (along with retinopathy and damage to the developing brain) as a result of inflammatory cascade involving increased ROS and decreased nitrous oxide production [25-27].

Surgical site infections (SSI) are the main causes of morbidity, mortality and increased cost of care amongst general surgical patients [28, 29]. Interventions to minimize the rate of these infections by optimizing blood flow and content have been focused mostly on surgical and patient-related factors; however, culprits related to anesthetic management, such as tissue perfusion, volume status, perioperative body temperature, blood transfusions and inspired oxygen concentration, have been investigated as well [30]. Adequate wound oxygen level is important for healing, but a rise in $\mathrm{FiO}_{2}$ alone alters these levels insignificantly and therefore its local benefits may be overrun by the systemic harm over-oxygenation causes [8].

Studies of the clinical impact of high $\mathrm{FiO}_{2}$ 's on the rate of SSI have shown inconsistent results. In one study amongst general surgical patients, exposure to high $\mathrm{FiO}_{2}$ during operations for about 200 minutes, and for 2 hours post-operatively resulted in higher infection rates and longer hospitalization [31]. Another trial found better anastomotic healing rates post-total gastrectomy 
when patients were ventilated with higher $\mathrm{FiO}_{2}$ during and for 6 hours after the operation [32]. On the other hand, Mayzler et al. observed no difference in the rates of surgical site infections during colorectal operations performed with either $30 \%$ or $80 \%$ oxygen [33]. Such conflicting results are numerous due to the great variation in the study designs as in these two examples. Meta-analysis of current literature with surgical site infection rate as primary outcome concludes no overall benefit of high $\mathrm{FiO}_{2}$ (except for a potential benefit for certain subgroups, i.e. if prophylactic antibiotics were used) and suggests even a potential harm [4].

During coronary artery bypass surgery, use of a high $\mathrm{FiO}_{2}$ to obtain hyperoxemia does not offer any benefits over lower $\mathrm{FiO}_{2}$ 's with normal arterial oxygen levels in terms of degree of myocardial damage and mortality outcome [6]. A high $\mathrm{FiO}_{2}$ decreases gas microembolism formation in the cardiopulmonary bypass, but whether this translates into a clinical benefit is unclear [34]. Pre-conditioning the healthy heart to hyperoxia before a cardiopulmonary bypass may improve outcomes after a transient global ischemia. However, this is likely due to increased anti-oxidant mechanisms from pre-conditioning [6]. Hyperoxia has been shown to increase infarct size and mortality after myocardial ischemia and cerebral infarct as well [10, 35].

Postoperative nausea and vomiting (PONV) is a common complication in perioperative period and several factors contribute to its development. Reduction of PONV has been observed in patients undergoing colorectal surgery with high $\mathrm{FiO}_{2}$ [36]; however, overall consensus from meta-analyses conclude that effect of $\mathrm{FiO}_{2}$ on $\mathrm{PONV}$ is minimal and there is not sufficient evidence to promote its use as a prophylactic measure [8].

Due to its potential harm, oxygen should be used carefully in post-operative and critical care areas as well. Based on current evidence, post-operative oxygen therapy should aim $\mathrm{SpO}_{2}$ levels of $88-94 \%$ for preterm neonates, $95 \%$ for infants, above $95 \%$ for children and elderly, above $98 \%$ for adults and between $88-92 \%$ for COPD patients in order to achieve the minimum risk/benefit ratio [8]. Comprehensive clinical data to reach a consensus on whether hyperoxia affects the outcomes of critically ill patients remains insufficient. A meta-analysis only concludes that hyperoxia is associated with a greater mortality in mechanically ventilated post-cardiac arrest and stroke and traumatic injury subset of general ICU patients [37].

\section{Conclusion}

In summary, oxygen is an essential drug for treating or preventing hypoxemia perioperatively. The harm caused by excess $\mathrm{FiO}_{2}$ is almost always iatrogenic and can be prevented with careful use of oxygen. A recent review of current literature concludes that strong clinical evidence is insufficient for showing the benefit of high perioperative $\mathrm{FiO}_{2}$ and warns off its routine use due its potential detrimental effects $[2,4,36]$. Apart from solely increasing $\mathrm{FiO}_{2}$, tissue oxygenation can be improved by ensuring adequate alveolar ventilation, improved diffusion capacity of the lung, sufficient hemoglobin level and optimal metabolic status [1]. More goal and context specific randomized clinical trials using standard protocols are required to reach a better understanding.

\section{Conflict of interest}

Nothing to declare

\section{References}

1. O’Driscoll BR, Howard LS, Davison AG, British Thoracic Society. BTS guideline for emergency oxygen use in adult patients. Thorax 2008; 63 Suppl 6: vi1-68. DOI: 10.1136/thx.2008.102947

2. Decalmer S, O'Driscoll BR. Oxygen: friend or foe in perioperative care? Anaesthesia 2013; 68: 8-12. DOI: 10.1111/ anae. 12088

3. Applegate RL $2^{\text {nd }}$, Dorotta IL, Wells B, Juma D, Applegate PM. The Relationship Between Oxygen Reserve Index and Arterial Partial Pressure of Oxygen During Surgery. Anesth Analg 2016; 123: 626-633. DOI: 10.1213/ANE.0000000000001262

4. Wetterslev J, Meyhoff CS, Jřrgensen LN, Gluud C, Lindschou J, Rasmussen LS. The effects of high perioperative inspiratory oxygen fraction for adult surgical patients. Cochrane Database Syst Rev 2015; CD008884. DOI: 10.1002/ 14651858.CD008884.pub2

5. Orbegozo Cortés D, Puflea F, Donadello K, Taccone FS, Gottin L, Creteur J, et al. Normobaric hyperoxia alters the microcirculation in healthy volunteers. Microvasc Res 2015; 98: 23-28. DOI: $10.1016 /$ j.mvr.2014.11.006

6. Smit B, Smulders YM, de Waard MC, Boer C, Vonk AB, Veerhoek $\mathrm{D}$, et al. Moderate hyperoxic versus near-physiological oxygen targets during and after coronary artery bypass surgery: a randomised controlled trial. Crit Care 2016;20: 55. DOI: 10.1186/s13054-016-1240-6

7. Llitjos JF, Mira JP, Duranteau J, Cariou A. Hyperoxia toxicity after cardiac arrest: What is the evidence? Ann Intensive Care 2016; 6: 23. DOI: 10.1186/s13613-016-0126-8

8. Habre W, Peták F. Perioperative use of oxygen: variabilities across age. Br J Anaesth 2014; 113 Suppl 2: ii26-36. DOI: 10.1093/bja/aeu380

9. Niijima S, Shortland DB, Levene MI, Evans DH. Transient hyperoxia and cerebral blood flow velocity in infants born prematurely and at full term. Arch Dis Child 1988; 63: 11261130

10. Rønning OM, Guldvog B. Should stroke victims routinely receive supplemental oxygen? A quasi-randomized controlled trial. Stroke 1999; 30: 2033-2037

11. Koksal GM, Dikmen Y, Erbabacan E, Aydin S, Çakatay U, Sitar $\mathrm{ME}$, et al. Hyperoxic oxidative stress during abdominal surgery: a randomized trial. J Anesth 2016; 30: 610-619. DOI: 10.1007/ s00540-016-2164-7 
12. Auten RL, Davis JM. Oxygen toxicity and reactive oxygen species: the devil is in the details. Pediatr Res 2009; 66: 121127. DOI: 10.1203/PDR.0b013e3181a9eafb

13. Qadan M, Battista C, Gardner SA, Anderson G, Akca O, Polk HC Jr. Oxygen and surgical site infection: a study of underlying immunologic mechanisms. Anesthesiology 2010; 113: 369-377. DOI: $10.1097 /$ ALN.0b013e3181e19d1d

14. O’Reilly PJ, Hickman-Davis JM, Davis IC, Matalon S. Hyperoxia impairs antibacterial function of macrophages through effects on actin. Am J Respir Cell Mol Biol 2003; 28: 443-450. DOI: 10.1165/rcmb.2002-01530C

15. Phillips PG, Higgins PJ, Malik AB, Tsan MF. Effect of hyperoxia on the cytoarchitecture of cultured endothelial cells. Am J Pathol 1988; 132: 59-72

16. Gupta S, Laskar N, Kadouri DE. Evaluating the Effect of Oxygen Concentrations on Antibiotic Sensitivity, Growth, and Biofilm Formation of Human Pathogens. Microbiol Insights 2016; 9: 37-46. DOI: 10.4137/MBI.S40767

17. Mižíková I, Ruiz-Camp J, Steenbock H, Madurga A, Vadász I, Herold S, et al. Collagen and elastin cross-linking is altered during aberrant late lung development associated with hyperoxia. Am J Physiol Lung Cell Mol Physiol 2015; 308: L1145-1158. DOI: 10.1152/ajplung.00039.2015

18. Wagner PD, Laravuso RB, Uhl RR, West JB. Continuous distributions of ventilation-perfusion ratios in normal subjects breathing air and $100 \% \mathrm{O}_{2}$. J Clin Invest 1974; 54: 54-68. DOI: 10.1172/JCI1 07750

19. Edmark L, Kostova-Aherdan K, Enlund M, Hedenstierna G. Optimal oxygen concentration during induction of general anesthesia. Anesthesiology 2003; 98: 28-33. DOI: $0000542-$ 200301000-00008

20. Rothen HU, Sporre B, Engberg G, Wegenius G, Högman M, Hedenstierna G. Influence of gas composition on recurrence of atelectasis after a reexpansion maneuver during general anesthesia. Anesthesiology 1995; 82: 832-842.

21. Budinger GR, Mutlu GM, Urich D, Soberanes S, Buccellato LJ, Hawkins K, et al. Epithelial cell death is an important contributor to oxidant-mediated acute lung injury. Am J Respir Crit Care Med 2011; 183: 1043-1054. DOI: 10.1164/rccm.201002$01810 \mathrm{C}$

22. Sackner MA, Landa J, Hirsch J, Zapata A. Pulmonary effects of oxygen breathing. A 6-hour study in normal men. Ann Intern Med 1975; 82: 40-43

23. Carpagnano GE, Kharitonov SA, Foschino-Barbaro MP, Resta O, Gramiccioni E, Barnes PJ. Supplementary oxygen in healthy subjects and those with COPD increases oxidative stress and airway inflammation. Thorax 2004; 59: 1016-1019. DOI: $10.1136 /$ thx. 2003.020768

24. Olivant Fisher A, Husain K, Wolfson MR, Hubert TL, Rodriguez E, Shaffer TH, et al. Hyperoxia during one lung ventilation: inflammatory and oxidative responses. Pediatr Pulmonol 2012; 47: 979-986. DOI: 10.1002/ppul.22517
25. Lopez E, Boucherat O, Franco-Montoya ML, Bourbon JR, Delacourt C, Jarreau PH. Nitric oxide donor restores lung growth factor and receptor expression in hyperoxia-exposed rat pups. Am J Respir Cell Mol Biol 2006; 34: 738-745. DOI: 10.1165/ rcmb.2005-0254OC

26. Sola A. Oxygen in neonatal anesthesia: friend or foe? Curr Opin Anaesthesiol 2008; 21: 332-339. DOI: 10.1097/ ACO.0b013e3282f8ad8d

27. Wai KC, Kohn MA, Ballard RA, Truog WE, Black DM, Asselin JM, et al. Early Cumulative Supplemental Oxygen Predicts Bronchopulmonary Dysplasia in High Risk Extremely Low Gestational Age Newborns. J Pediatr 2016; 177: 97-102. e2. DOI: $10.1016 /$ j.jpeds.2016.06.079

28. Kirkland KB, Briggs JP, Trivette SL, Wilkinson WE, Sexton DJ. The impact of surgical-site infections in the 1990s: attributable mortality, excess length of hospitalization, and extra costs. Infect Control Hosp Epidemiol 1999; 20: 725-730. DOI: $10.1086 / 501572$

29. Global Guidelines for the Prevention of Surgical Site Infection. Geneva: World Health Organization; 2016

30. Buggy D. Can anaesthetic management influence surgical-wound healing? Lancet 2000; 356: 355-357. DOI: 10.1016/S01406736(00)02523-X

31. Pryor KO, Fahey TJ $3^{\text {rd }}$, Lien CA, Goldstein PA. Surgical site infection and the routine use of perioperative hyperoxia in a general surgical population: a randomized controlled trial. JAMA 2004; 291: 79-87. DOI: 10.1001/jama.291.1.79

32. Schietroma M, Cecilia EM, Carlei F, Sista F, De Santis G, Piccione F, et al. Prevention of anastomotic leakage after total gastrectomy with perioperative supplemental oxygen administration: a prospective randomized, double-blind, controlled, single-center trial. Ann Surg Oncol 2013; 20: 1584-1590. DOI: 10.1245/ s10434-012-2714-7

33. Mayzler O, Weksler N, Domchik S, Klein M, Mizrahi S, Gurman GM. Does supplemental perioperative oxygen administration reduce the incidence of wound infection in elective colorectal surgery? Minerva Anestesiol 2005; 71: 21-25

34. Young RW. Hyperoxia: a review of the risks and benefits in adult cardiac surgery. J Extra Corpor Technol 2012; 44: 241-249

35. Janz DR, Hollenbeck RD, Pollock JS, McPherson JA, Rice TW. Hyperoxia is associated with increased mortality in patients treated with mild therapeutic hypothermia after sudden cardiac arrest. Crit Care Med 2012; 40: 3135-3139. DOI: 10.1097/ CCM.0b013e3182656976

36. Greif R, Laciny S, Rapf B, Hickle RS, Sessler DI. Supplemental oxygen reduces the incidence of postoperative nausea and vomiting. Anesthesiology 1999; 91: 1246-1252

37. Damiani E, Adrario E, Girardis M, Romano R, Pelaia P, Singer $\mathrm{M}$, et al. Arterial hyperoxia and mortality in critically ill patients: a systematic review and meta-analysis. Crit Care 2014; 18: 711. DOI: $10.1186 / \mathrm{s} 13054-014-0711-\mathrm{x}$ 